\title{
CARACTERIZAÇÃO HIDROQUÍMICA DO AQÜÍFERO GUARANI NA PORÇÃO CENTRO-NORTE DO ESTADO DO PARANÁ, BRASIL.
}

\author{
Ernani Francisco da Rosa Filho ${ }^{1}$, André Virmond Lima Bittencourt ${ }^{2}$, \\ Eduardo Chemas Hindi ${ }^{1}$ e Ramon Aravena ${ }^{3}$
}

\begin{abstract}
RESUMO Embora muito se fale no potencial e na excelente qualidade das águas armazenadas no Sistema Aqüífero Guarani (SAG), variações espaciais significativas nas propriedades hidrogeológicas e hidroquímicas relaciodadas a feições geológicas e estruturais localizadas, podem ocasionar resultados negativos inesperados, tanto em termos de quantidade, como na qualidade da água captada. A classificação hidroquímica (considerando os íons predominantes) da água com base em dados de análises físico-químicas de doze amostras de água coletadas em poços que captam águas do SAG, situados na porção centro-norte do Estado do Paraná, e em zona de influência do Arco de Ponta Grossa, permitiu individualizar as seguintes famílias: bicarbonatada-cálcica (Cambará, Santa Amélia e Abatia); bicarbonatada-sódica (Londrina, Cornélio Procópio, e Bandeirantes); bicarbonatada-sódica com teor mais elevado de cálcio (Andirá); mista-sódica (BandeirantesYara) e sulfatada-cloretada-sódica (Jardim Alegre). Algumas dessas famílias são resultantes de processos de evolução geoquímica causados pela migração da água através do aqüífero, enquanto outras (Jardim Alegre), podem ser interpretadas como resultado de um tempo de residência prolongado, relativamente às outras porções do aqüífero, por estar sendo captada em compartimento isolado, limitado por falhamentos e intrusões de diques de diabásio. A relação entre a qualidade e quantidade da água armazenada e a possibilidade de compartimentação do arcabouço do aqüífero deve ser levada em conta para não inviabilizar projetos de captação do SAG para fins de abastecimento público.
\end{abstract}

Palavras chave: Sistema Aqüífero Guarani, Arco de Ponta Grossa, qualidade de água

ABSTRACT Although there is a common sense about the water quality and quantity stored in the Guarani Aquifer System (GAS), the spatial variability of the aquifer hydrogeological and hydrochemical properties related to geological and structural features may lead to unexpected negative results in both, quality and quantity parameters. Chemical analysis data from twelve water samples collected from wells placed in center-north region of Paraná State and under the tectonic influence of Ponta Grossa Arch, indicates five water types in the aquifer, according to the ionic predominance, as follow: calcium-bicarbonate (Cambará, Santa Amélia and Abatia); sodium-bicarbonate (Londrina, Cornélio Procópio, and Bandeirantes); sodium-bicarbonate with higher sodium content (Andirá); sodium-mixed type (Bandeirantes-Yara) and sodium-sulfate-chloride (Jardim Alegre). Some of these water types result from the water hydrochemical evolution along regional flow path. Others can be attributed to long residence time, when compared to other portion of the GAS, being the water stored in a closed compartiment, limited by faults and diabase dykes, as Jardim Alegre case. The exploitation of the GAS must consider the possibility of such compartiments in order to avoid failures in water supply projects.

Keywords: Guarani Aquifer, Ponta Grossa Arch, water quality

\section{INTRODUÇÃO}

Aqüíferos que apresentam compartimentação física causada por barreiras estruturais (falhamentos ou intrusões de rochas magmáticas), quando submetidos a explotação, podem sofrer rápido abatimento da potenciometria e esgotamento da água armazenada. Além disso, pela baixa taxa de renovação de suas águas, estas podem apresentar alto teor de substâncias dissolvidas que, em certos casos, chegam a inviabilizar o seu uso para de abastecimento público.

Quando se faz menção ao Sistema Aqüífero Guarani (SAG), as opiniões são unânimes, sobre seu elevado potencial hidrogeológico e sobre a excelente qualidade da sua água. Destaca-se, entretanto, que tal conceito não deve ser tomado como regra geral, uma vez que existem variações espaciais significativas nas propriedades hidrogeológicas e hidroquímicas do SAG, em função das características geológicas e estruturais locais. Não avaliar, em projetos de explotação do SAG, os possíveis efeitos de feições geoestruturais no fluxo e armazenamento da água subterrânea, pode ocasionar resultados negativos inesperados, tanto em termos de quantidade, como na qualidade da água captada.

Com o objetivo de se buscar uma melhor compreensão sobre os efeitos da compartimentação do SAG, causada por falhamentos e intrusões de diques de diabásio, na qualidade da água, foram comparados e interpretados os resultados analíticos de amostras de água coletadas em poços, situados em zonas de influência do Arco de Ponta Grossa,

\footnotetext{
${ }^{1}$ LPH - Laboratório de Pesquisas Hidrogeológicas - Depto. de Geologia - Universidade Federal do Paraná (ernani@ufpr.br)e (hindi@ufpr.br)

${ }^{2}$ LPH - Degeol-UFPR / UNICENP - Centro Universitário Positivo (andre@ufpr.br)

${ }^{3}$ Department of Earth Sciences, University of Waterloo, Canadá (roaraven@scimail.uwaterloo.ca)
} 
perfurados nas seguintes cidades: Santa Amélia, Londrina, Cornélio Procópio, Bandeirantes, Cambará, Abatia, Andirá e Jardim Alegre, todas localizadas no Estado do Paraná.

\section{CONTEXTO HIDROGEOLÓGICO}

A região compreendida entre os alinhamentos do Rio Alonzo e São Jerônimo-curiuva é a mais estruturada segundo as feições magnéticas e estruturais relacionadas ao Arco de Ponta Grossa (alinhamentos de Guapiara e Rio Piquiri), porque está inserida na zona de charneira da referida estrutura (STRUGALLE et al., 2002). Em algumas áreas desta região o referido arqueamento causou intensos falhamentos geológicos, sendo notórias, também, as intrusões de diques de diabásios resultantes desse evento tectônico. Por conta disso, o SAG é localmente descontínuo e não raramente encontra-se em contato lateral com as formações Rio do Rasto e Serra geral, o que impossibilita uma conexão hidráulica entre uma e outra porção do aqüífero (Figura 1). Destaque-se ainda que a pressão hidráulica entre o pacote superior (Formação Serra Geral) e o pacote inferior (Formação Botucatu) é, em quase todos os casos, ascendente, mas raramente verificam-se valores superiores ao da cota da superfície do terreno.

As falhas mais proeminentes apresentam direção N40-60E e N40-50W estando estas últimas, em muitos casos, preenchidas por diques de diabásios (STRUGALLE et al., 2002). O sistema de falhas geológicas, juntamente com os diques de diabásio, configuram compartimentos com forma aproximada de romboédros.

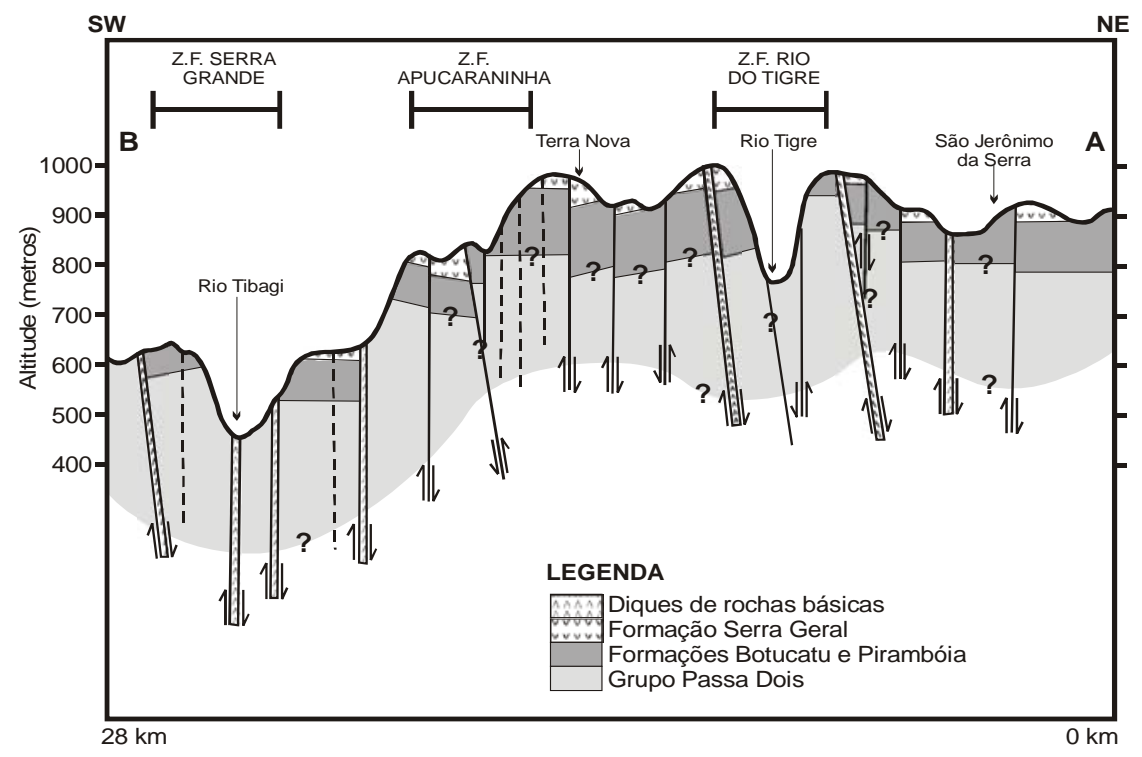

Figura 1 - Contatos entre as Formações Botucatu e Pirambóia (SAG) e Formação Rio do Rasto (Grupo Passa Dois). Fonte: STRUGALLE et al.. (2002)

No Estado do Paraná, diferenças acentuadas entre as características hidráulicas, estratigráficas e hidroquímicas de poços relativamente próximos, que captam águas do SAG, podem ser interpretadas como resultados de condições estruturais particulares que causaram uma compartimentação do aqüífero. Como exemplo dessa possível compartimentação, cita-se o exemplo do poço jorrante de Santa Amélia Laranjinha, situado no flanco norte do Arco de Ponta Grossa, que atingiu o SAG com apenas 39 $\mathrm{m}$ de profundidade, apresentando vazão de surgência estimada em $150 \quad \mathrm{~m}^{3} / \mathrm{h}$. Em contrapartida, poços situados nas proximidades, como Abatia (15 km a sudeste de Santa Amélia) e Bandeirantes (20 km ao norte de Santa Amélia), atingiram o SAG a profundidades de 136 e $404 \mathrm{~m}$ respectivamente. Nessas duas últimas cidades, o aqüífero apresenta características semi-artesianas, com nível estático a $80 \mathrm{~m}$ de profundidade em Abatia e a $64 \mathrm{~m}$ em Bandeirantes.

Outro caso típico de compartimentação do SAG é o poço perfurado em Jardim Alegre (flanco sul do Arco de Ponta Grossa) que, ainda na fase de teste, apresentou queda acentuada de vazão, constatando-se, posteriormente, que o local da perfuração estava situado entre duas intrusões de diabásio, uma situada a uma 
distância de 100 m para o sul e a outra 500 m para norte (SANEPAR, 2001)

\section{MATERIAL E MÉTODOS}

As amostras de água do SAG, utilizadas neste trabalho, foram coletadas nas cidades de Santa Amélia, Londrina, Cornélio Procópio, Bandeirantes, Cambará, Abatia, Andirá e Jardim Alegre, em poços utilizados para abastecimento doméstico, recreativo e industrial. A localização dessas cidades está apresentada na figura 2.

Os locais de coleta, bem como os valores dos parâmetros determinados estão apresentados na tabela 1.
Os parâmetros $\mathrm{pH}$, temperatura, condutividade elétrica e alcalinidade foram determinados no campo. Os demais parâmetros foram analisados no Laboratório de Pesquisas Hidrogeológicas da Universidade Federal do Paraná.

A classificação da água foi feita pelo método de íons predominantes e representada graficamente, através do diagrama de Durov modificado.

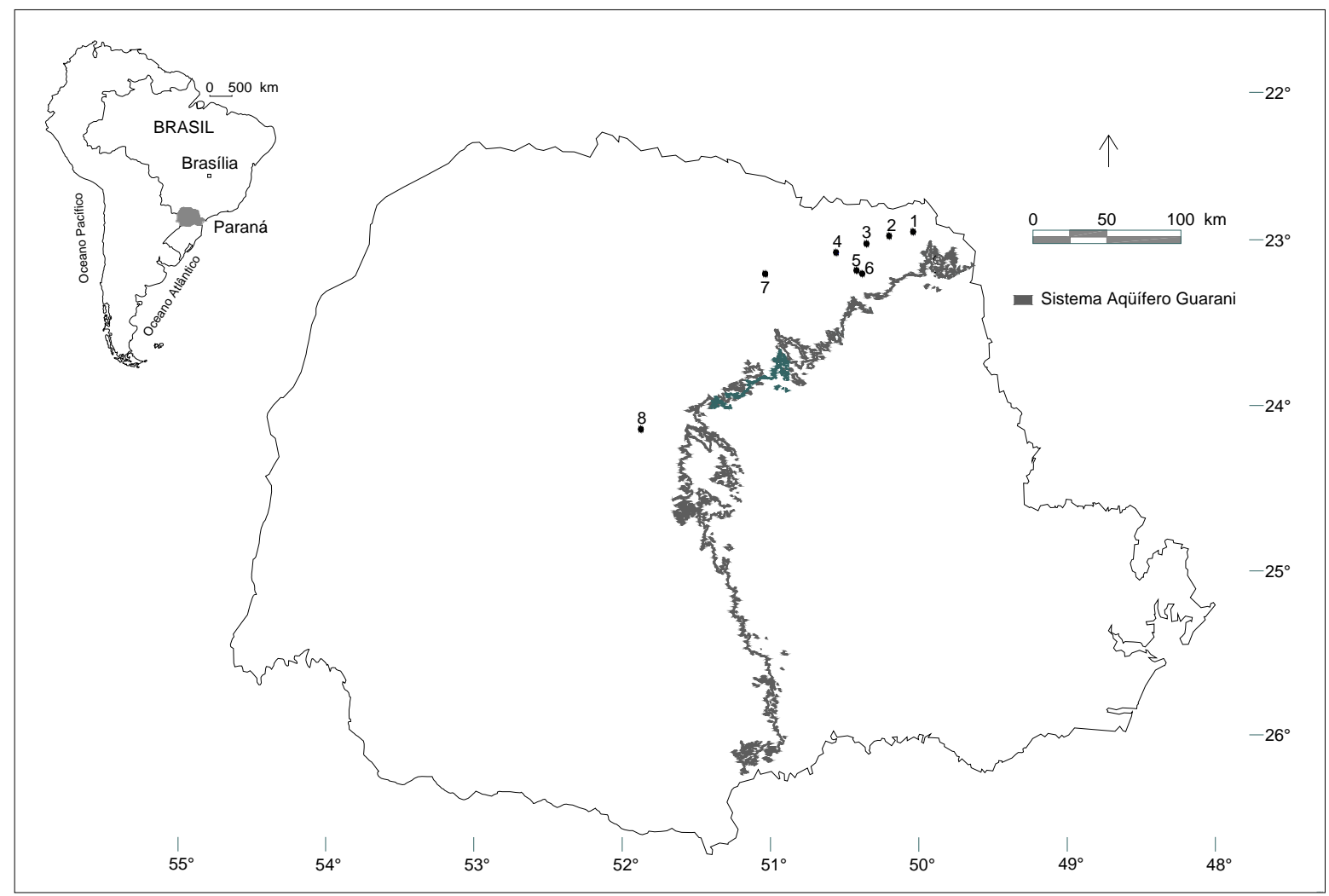

Figura 2 - Mapa de localização das cidades onde foram feitas as coletas de amostras de água (1-Cambará; 2-Andirá; 3-Bandeirantes; 4-Cornélio Procópio; 5-Santa Amélia; 6-Abatiá; 7-Londrina e 8-Jardim Alegre) 


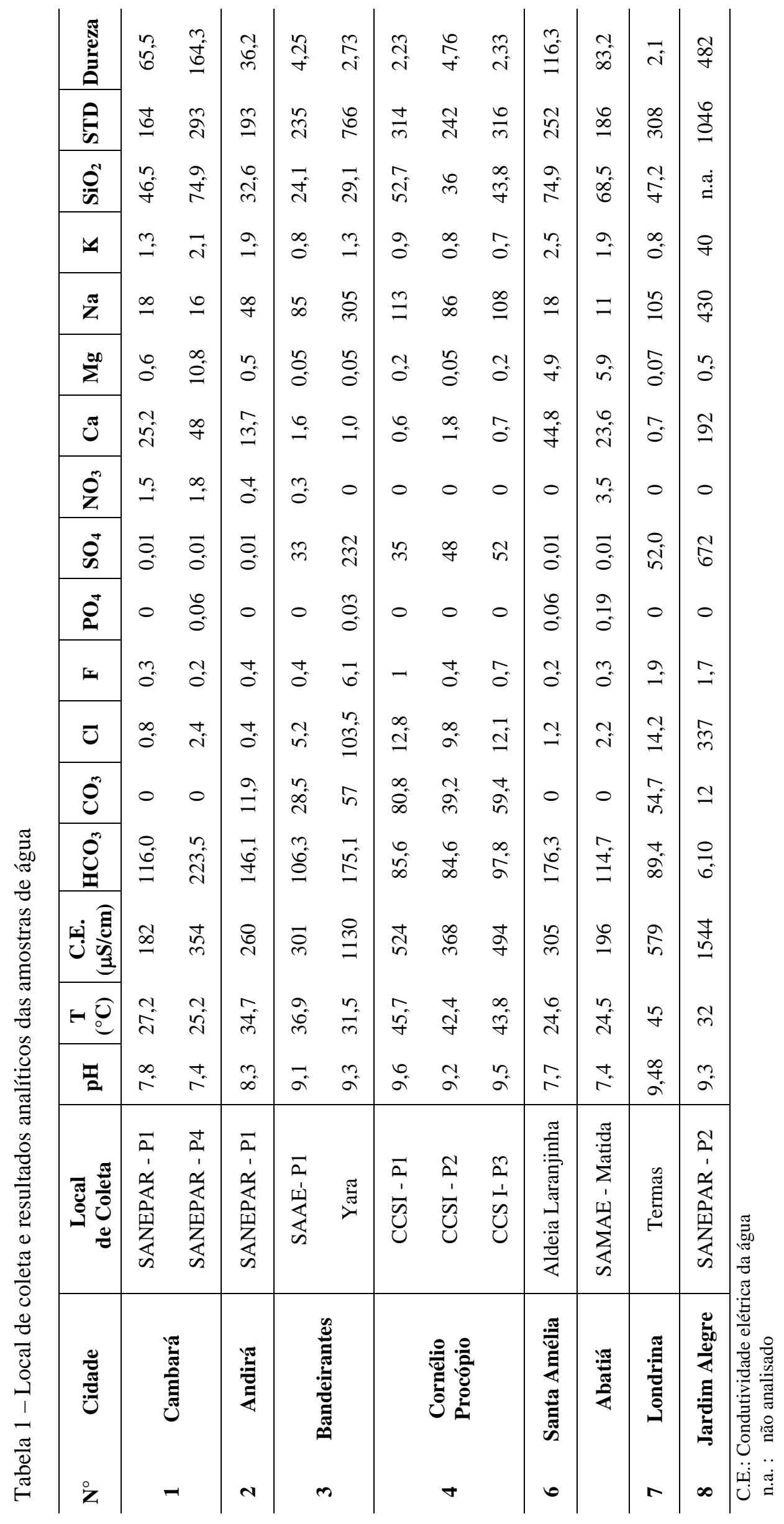




\section{RESULTADOS E DISCUSSÃO}

Com base nos resultados analíticos, foram individualizadas cinco famílias de águas:

- Água bicarbonatada-cálcica (Cambará, Santa Amélia e Abatia);

- Água bicarbonatada-sódica (Londrinatermas, Cornélio Procópio, e Bandeirantes);
- Água bicarbonatada-sódica com teor mais elevado de cálcio (Andirá)

- Água mista-sódica (Bandeirantes-Yara).

- Água sulfatada-cloretada-sódica (Jardim Alegre)

O diagrama de Durov modificado (Figura 3), ilustra as relações entre os íons principais e as diferentes famílias de água.

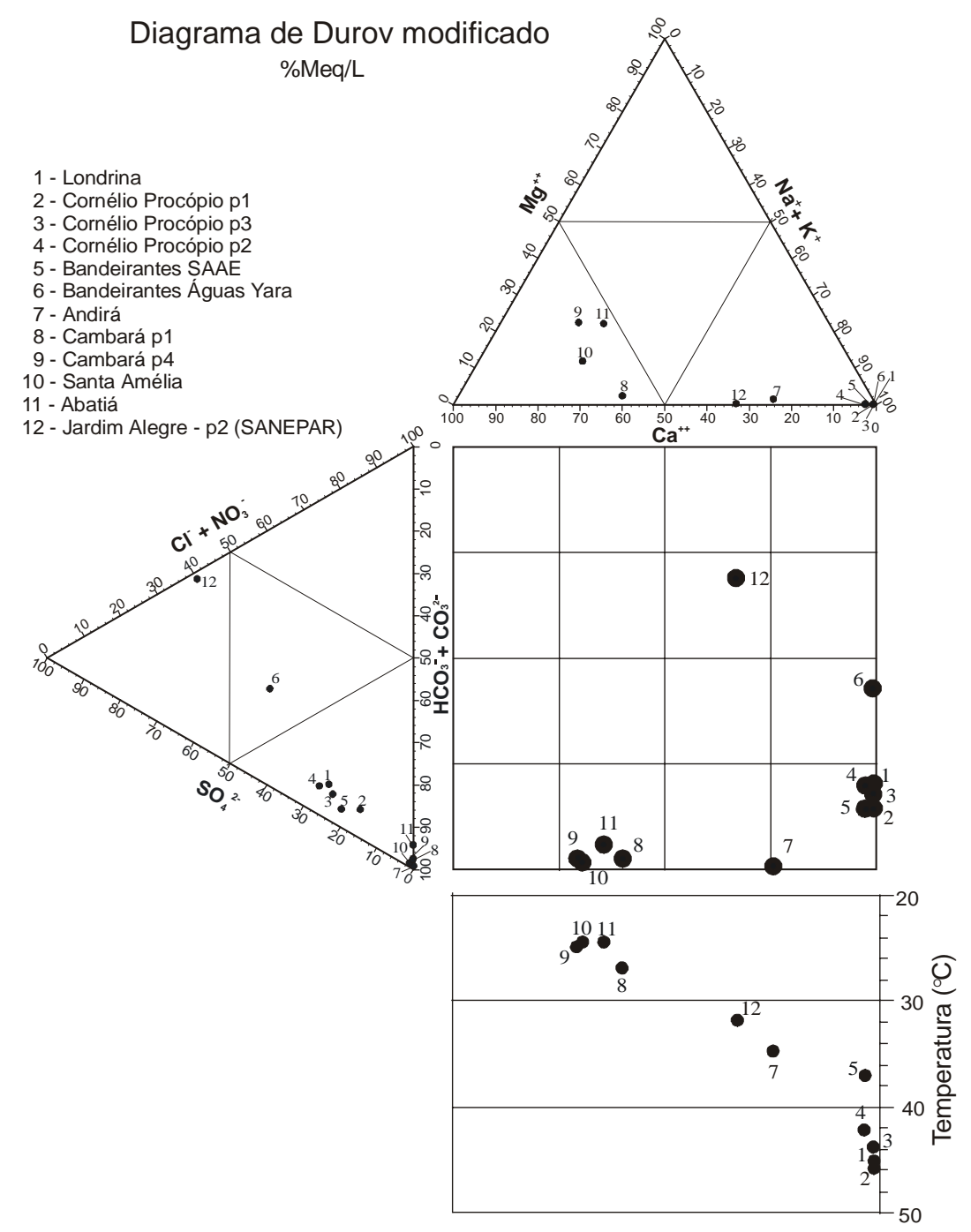

Figura 3 - Inter-relações entre os componentes iônicos mais abundantes.

As águas bicarbonatadas são aquelas que apresentam temperaturas mais baixas, enquanto as águas sódicas correspondem a temperaturas mais elevadas.

As águas de Jardim Alegre apresentam temperaturas intermediárias, porém seu quimismo atesta uma evolução hidroquímica particular. Certamente não se trata do produto de misturas simples, ou um estágio intermediário de evolução entre extremos bicarbonatado cálcico e sulfatado cloretado sódico. É uma água que seguiu uma evolução própria em um compartimento geoestrutural específico, onde níveis de saturação por equilíbrios com minerais controlam o quimismo. 
Os fluoretos estão presentes em todas as águas, sendo que o valor médio das doze amostras coletadas é igual a $1,07 \mathrm{mg} / \mathrm{L}$ e a variação situa-se entre $0,15 \mathrm{mg} / \mathrm{L}$ e 6,1 mg/L.

Na família de água bicarbonatada cálcica não foi detectada a presença de carbonatos e de sulfatos, sendo que o maior valor do $\mathrm{pH}$ foi igual a 7,81 e os sólidos totais dissolvidos variaram entre 164 e $293 \mathrm{mg} / \mathrm{L}$. Os bicarbonatos situam-se entre 114,7 e $223,5 \mathrm{mg} / \mathrm{L}$ e os cloretos entre 0,8 $\mathrm{mg} / \mathrm{L}$ e $2,4 \mathrm{mg} / \mathrm{L}$. Com relação aos cátions, os teores de cálcio variam de 23,6 mg/L a 48,0 $\mathrm{mg} / \mathrm{L}$, de magnésio entre $0,6 \mathrm{mg} / \mathrm{L}$ e $10,8 \mathrm{mg} / \mathrm{L}$, de sódio entre $11,4 \mathrm{mg} / \mathrm{L}$ e $18,3 \mathrm{mg} / \mathrm{L}$ e de potássio entre $1,3 \mathrm{mg} / \mathrm{L}$ e $2,5 \mathrm{mg} / \mathrm{L}$. A temperatura da água na boca do poço variou de $24,5^{\circ} \mathrm{C}$ a $27,2^{\circ} \mathrm{C}$.

Na família de água bicarbonatada sódica os sulfatos variam entre $33 \mathrm{mg} / \mathrm{L}$ e $52 \mathrm{mg} / \mathrm{l}$, os carbonatos variam entre $28,5 \mathrm{mg} / \mathrm{L}$ e $80,78 \mathrm{mg} / \mathrm{L}$, sendo que o pH varia entre 9,1 e 9,56 e os sólidos totais dissolvidos entre $235 \mathrm{mg} / \mathrm{L}$ e $314 \mathrm{mg} / \mathrm{L}$. Os bicarbonatos variam entre 85,6 mg/L e 106,3 $\mathrm{mg} / \mathrm{L}$ e os cloretos entre 5,2 mg/L e 14,2 mg/L. Predominando acentuadamente o sódio, seus teores variam entre $84,5 \mathrm{mg} / \mathrm{L}$ e $112,5 \mathrm{mg} / \mathrm{L}$, o potássio de $0,7 \mathrm{mg} / \mathrm{L}$ e os demais cátions como o cálcio e o magnésio os teores variam entre 0,6 $\mathrm{mg} / \mathrm{L}$ e $1,6 \mathrm{mg} / \mathrm{L}$ e entre $0,05 \mathrm{mg} / \mathrm{L}$ e $0,2 \mathrm{mg} / \mathrm{L}$, respectivamente. A temperatura da água varia de 34,7 a $45,7^{\circ} \mathrm{C}$.

A família de água sulfatada bicarbonatada sódica é representada apenas pela amostra coletada em Bandeirantes-Yara, que se acha a uma distância de $10 \mathrm{~km}$ do poço SAAE-P1. O pH é igual a 9,3 e os sólidos totais dissolvidos apresentam um teor de $766 \mathrm{mg} / \mathrm{L}$. O teor de sulfato é igual a $232 \mathrm{mg} / \mathrm{L}$, de bicarbonato 175,1 $\mathrm{mg} / \mathrm{L}$, de carbonato $57,0 \mathrm{mg} / \mathrm{L}$ e de cloreto 103,5 $\mathrm{mg} / \mathrm{L}$. É nesta fonte que ocorre a maior concentração de fluoretos, de $6,1 \mathrm{mg} / \mathrm{L}$. O teor de sódio é de 305,0 $\mathrm{mg} / \mathrm{L}$, de potássio 1,3 $\mathrm{mg} / \mathrm{L}$, de cálcio $1,01 \mathrm{mg} / \mathrm{L}$ e de magnésio $0,05 \mathrm{mg} / \mathrm{L}$. A temperatura da água é igual a $31,5^{\circ} \mathrm{C}$.

A água do tipo sulfatada cloretada sódica está representada apenas pela amostra coletada no poço II de Jardim Alegre. O pH é igual a 9,3 e os sólidos totais dissolvidos apresentam um valor igual a $1046 \mathrm{mg} / \mathrm{L}$. O teor de sulfato é igual a $672,4 \mathrm{mg} / \mathrm{L}$, de cloreto $337 \mathrm{mg} / \mathrm{L}$, enquanto os bicarbonatos apresentam um teor de apenas 6,1 $\mathrm{mg} / \mathrm{L}$ e os carbonatos $12 \mathrm{mg} / \mathrm{L}$. O teor de sódio é igual a $430 \mathrm{mg} / \mathrm{L}$, de cálcio 192,4 mg/L, de potássio $40 \mathrm{mg} / \mathrm{L}$ e de magnésio $0,5 \mathrm{mg} / \mathrm{L}$. A temperatura da água é igual a $32{ }^{\circ} \mathrm{C}$.

Sob o enfoque hidroquímico, para a finalidade de comparação de resultados, considerou-se suficiente uma avaliação sobre as conclusões dos estudos desenvolvidos por SILVA (1983).

Os resultados das análises físico-químicos interpretados por SILVA (1983) mostram que as águas são fracamente salinas, com resíduo seco a $105{ }^{\circ} \mathrm{C}$ inferior a $250 \mathrm{mg} / \mathrm{L}$ em 84\% das amostras, sendo que à medida que aumenta o confinamento do aqǘ́fero e o tempo de residência das águas, resulta num enriquecimento em sólidos dissolvidos. A temperatura máxima da água atinge $63{ }^{\circ} \mathrm{C}$ em Presidente Prudente-SP. As três fácies hidroquímicas transicionais, identificadas nesse trabalho são (a) na porção livre do aqüífero: predominam águas bicarbonatadas-magnesianas e calciomagnesianas, com teor de sólidos totais dissolvidos inferior a $100 \mathrm{mg} / \mathrm{L}$ e temperaturas entre 22 e $25{ }^{\circ} \mathrm{C}$; (b) nas áreas de conectividade com a Formação Serra Geral: as águas são bicarbonatadas-cálcicas e calcio-magnesianas, com teor de sólidos totais dissolvidos em torno de $200 \mathrm{mg} / \mathrm{L}$ e temperatura até $30^{\circ} \mathrm{C}$; e (c) nas áreas francamente confinadas do aqüífero - as águas são bicarbonatadas-sódicas, evoluindo para cloro-sulfatadas-sódicas, com teor de sólidos totais dissolvidos em torno de $650 \mathrm{mg} / \mathrm{L}$ e temperaturas de até $63^{\circ} \mathrm{C}$.

A família de águas bicarbonatadas-cálcicas e calcio-magnesianas apresenta valores de $\mathrm{pH}$ inferior a 7,5, sendo que os teores de cálcio situam-se entre 0,8 e $50,3 \mathrm{mg} / \mathrm{L}$, os de sódio entre 0 e $20,0 \mathrm{mg} / \mathrm{L}$, os de potássio entre 0,8 e 6,6 $\mathrm{mg} / \mathrm{L}$, e os de magnésio valores inferiores a 13,7 $\mathrm{mg} / \mathrm{L}$. Quanto aos anions, o bicarbonato apresenta valores superiores a 3,7 $\mathrm{mg} / \mathrm{L}$ com um máximo de 192,8 mg/L, o carbonato possui valores inferiores a $1,2 \mathrm{mg} / \mathrm{L}$, o sulfato é sempre menor do que $10,1 \mathrm{mg} / \mathrm{L}$ e o cloreto menor do que $11,0 \mathrm{mg} / \mathrm{L}$.

A família das águas bicarbonatadas sódicas apresenta valores de $\mathrm{pH}$ entre 8,15 e 10,35. Quanto aos cátions, o sódio varia de 12,9 a 225,1 $\mathrm{mg} / \mathrm{L}$, o cálcio entre 0,4 e $16,8 \mathrm{mg} / \mathrm{L}$, o potássio entre 0,4 e $4,7 \mathrm{mg} / \mathrm{L}$ e o magnésio é sempre inferior a $1,0 \mathrm{mg} / \mathrm{L}$. Nos anions, os teores de bicarbonato estão compreendidos no intervalo entre 40,3 e 207,4 $\mathrm{mg} / \mathrm{L}$, estando sempre associados aos íons carbonatos cujos teores são sempre inferiores a $87,0 \mathrm{mg} / \mathrm{L}$, o sulfato apresenta concentração menor do que $92,2 \mathrm{mg} / \mathrm{L}$ e o cloreto varia entre 0,4 e 132,9 mg/L.

As relações iônicas, a exemplo de $\mathrm{rK} / \mathrm{rNa}$, $\mathrm{rCl} / \mathrm{rHCO}_{3}$ e $\mathrm{rSO}_{4} / \mathrm{rCl}$, são formas de medidas de verificação da salinização das águas. Com um valor de 0,003 a 3,72 para rK/rNa, SILVA 
(1983) destaca que existe uma tendência de diminuir com o maior confinamento do aqüífero. Já para as relações de $\mathrm{rCl} / \mathrm{rHCO}_{3}$ e de $\mathrm{rSO}_{4} / \mathrm{rCl}$, menciona que existe um aumento da concentração salina das águas no sentido preferencial do fluxo subterrâneo, estando seus valores variando de 0 a 1,10 e 0 a 2,84, respectivamente.

Apenas duas famílias de águas se assemelham entre aquelas analisadas no Estado de São Paulo em relação às águas sob a influência do Arco de Ponta Grossa: (a) as águas bicarbonatadas cálcicas; e (b) as águas bicarbonatadas sódicas. As águas sulfatadas bicarbonatas sódicas não foram detectadas no Estado de São Paulo. Na tabela 2 são apresentados os valores comparativos respectivos entre as águas analisadas.

Tabela 2 - Comparação entre valores de relações iônicas, sólidos totais dissolvidos e temperatura de águas de poços do SAG coletadas nos Estados de São Paulo e Paraná

\begin{tabular}{|c|c|c|c|c|c|c|c|c|c|c|}
\hline \multirow{2}{*}{$\begin{array}{l}\text { Parâmetros } \\
\text { Tipologia }\end{array}$} & \multicolumn{2}{|c|}{$\mathrm{rK} / \mathrm{rNa}$} & \multicolumn{2}{|c|}{$\mathrm{rCl} / \mathrm{rHCO}_{3}$} & \multicolumn{2}{|c|}{$\mathrm{rSO}_{4} / \mathrm{rCl}$} & \multicolumn{2}{|c|}{$\begin{array}{l}\text { STD } \\
(\mathrm{mg} / \mathrm{L})\end{array}$} & \multicolumn{2}{|c|}{$\begin{array}{c}\mathrm{T} \\
\left({ }^{\circ} \mathrm{C}\right)\end{array}$} \\
\hline & SP & PR & SP & PR & SP & PR & SP & PR & SP & PR \\
\hline $\begin{array}{l}\text { Bicarbonatada } \\
\text { Cálcica }\end{array}$ & 0,014 & 0,102 & 0,019 & 0,032 & 0,143 & 0,170 & 164 & 186 & 25,2 & 24,5 \\
\hline $\begin{array}{l}\text { Bicarbonatada } \\
\text { Sódicas }\end{array}$ & 0,024 & 0,054 & 0,004 & 0,080 & 1,00 & 4,60 & 193 & 235 & 34,7 & 36,9 \\
\hline
\end{tabular}

A relação menos elevada dos valores de $\mathrm{rK} / \mathrm{rNa}$ e mais elevadas de $\mathrm{rCl} / \mathrm{rHCO}_{3}$, e de $\mathrm{rSO}_{4} / \mathrm{rCl}$, assim como a concentração mais expressiva de sólidos totais dissolvidos e da temperatura das águas bicarbonatadas sódicas, em relação às águas bicarbonatadas cálcicas, mostram um maior confinamento nas situações hidrogeológicas de Londrina, Cornélio Procópio e Bandeirantes. Excetuando-se a fonte natural existente em Bandeirantes-Yara, cuja água é classificada como sulfatada bicarbonatada sódica, as demais localidades (Andirá, Cambará, Santa Amélia e Abatia) encontram-se em situação hidrogeológica em que, aparentemente, o SAG encontra-se em conexão direta com o ciclo hidrológico, de modo que os processos de recarga são mais efetivos nessas áreas.
Como se verifica na tabela 3 , caso específico do poço de Jardim Alegre, que atingiu o aqüífero a uma profundidade de $384 \mathrm{~m}$, a relação de $\mathrm{rK} / \mathrm{rNa}$ indica que o aqüífero está mais confinado do que numa situação onde ocorrem águas bicarbonatadas, mesmo com predominância do sódio em relação ao cálcio. A relação de $\mathrm{rCl} / \mathrm{rHCO}_{3}$, em especial, e a sua associação com o elevado teor de sólidos totais dissolvidos, mostra uma tipologia completamente diferente de todas as demais águas; este tipo de relação é indicativo de um tempo extremamente elevado de residência da água no reservatório, inclusive com pouca ou quase nenhuma contribuição de águas mais modernas.

Tabela 3 - Valores de relações iônicas, sólidos totais dissolvidos e temperatura da água do Poço-2 (Jardim Alegre)

\begin{tabular}{c|c|c|c|c|c}
\hline Tipologia & $\mathrm{rK} / \mathrm{rNa}$ & $\mathrm{RCl} / \mathrm{rHCO}_{3}$ & $\mathrm{rSO}_{4} / \mathrm{rCl}$ & $\begin{array}{c}\mathrm{STD} \\
(\mathrm{mg} / \mathrm{L})\end{array}$ & $\begin{array}{c}\mathrm{T} \\
\left({ }^{\circ} \mathrm{C}\right)\end{array}$ \\
\hline Sulfatada-Cloretada-Sódica & 0,0547 & 95,07 & 1,471 & 1046 & 32 \\
\hline
\end{tabular}




\section{DADOS ISOTÓPICOS}

Foram coletadas amostras de água para análise isotópica (Carbono-14), nos seguintes locais: Londrina (poço Termas); Cornélio Procópio (P3); Bandeirantes (Poço 1); Cambará (poço 1) e Santa Amélia (Laranjinha). Interpretações preliminares dos resultados dessas análises indicam idades de até 30.000 anos. Os resultados definitivos serão publicados oportunamente.

Esses valores, embora preliminares, são similares aos encontrados por SILVA (1983), também através da análise de Carbono-14 em amostras de água, correspondendo a idades de $30.000 \pm 1.900$ e $800 \pm 160$ anos. No mapa de distribuição da idade média aparente das águas do SAG no Estado de São Paulo, é mostrado que o aumento de idade da água, em direção ao interior da bacia é devido ao tempo de residência das águas no aqüífero. Destacam-se, ainda, idades elevadas, da ordem de 18.000 anos, próximas inclusive de zonas de afloramento do aqüífero, devido a presença de diques de diabásio e de descontinuidades geológicas que não permitem uma circulação mais elevada da água.

\section{CONCLUSÕES}

Os falhamentos e intrusões de diques de diabásio, na área em torno da charneira do Arco de Ponta Grossa, condicionam o fluxo subterrâneo e, conseqüentemente, a renovação da água armazenada no SAG. As variações de propriedades hidráulicas e das profundidades do topo do aqüífero em poços situados a menos de $20 \mathrm{~km}$ uns dos outros são indícios da movimentação de blocos e, conseqüente estruturação e compartimentação do arcabouço do aqüífero.

As diferentes famílias de águas, discriminadas neste trabalho, resultam não só da evolução geoquímica natural das águas ao longo de sua trajetória através do aqüífero, como também de condições geoestruturais particulares que confinam a água em reservatórios limitados, impondo tempos de residência mais prolongados, comparando-se a outras porções do SAG, causando uma maior concentração de sólidos totais dissolvidos.

\section{AGRADECIMENTOS}

Os autores agradecem ao $\mathrm{CNPq}$ (processo 550080) e a OEA (Fundo de Universidades) pelo apoio financeiro, sem o qual este trabalho não poderia ter sido desenvolvido.

\section{REFERÊNCIAS}

SANEPAR - Companhia de Saneamento do Paraná. Projeto Magnetometria do poço 2 Jardim Alegre/PR. Relatório preliminar. Curitiba: PR, 2001. 15 p.

SILVA, R. B. G. da Estudo Hidroquímico e isotópico das águas subterrâneas do aqǘfero Botucatu no Estado de São Paulo. 1983. 133 f. Tese (Doutorado em Geologia Geral e de Aplicação), Universidade de São Paulo, São Paulo: 1983.
STRUGALE, M.; ROSTIROLA, S. P.; ROSA FILHO, E.F. DA; HINDI, E.C.; MANCINI, F.; FERREIRA, F.J.F.; FREITAS, R. C. DE. Arcabouço estrutural do Arco de Ponta Grossa na região centro-norte do Estado do Paraná (Brasil): Implicações na hidrodinânimca do Sistema Aqüífero Guarani. In: CONGRESSO BRASILEIRO DE ÁGUAS SUBTERRÂNEAS, 12., 2002. Florianópolis, Anais... São Paulo: Associação Brasileira de Águas Subterrâneas. 1 CD-ROM 